\title{
Antibodies to extractable nuclear antigens (ENAS) in systemic lupus erythematosus
}

\author{
B. Joob ${ }^{1}$, V. Wiwanitkit ${ }^{2}$ \\ 'Sanitation 1, Medical Academic Center, Bangkok, Thailand; '2Dr DY Patil University, Pune, India
}

\footnotetext{
$\mathrm{D}$
}

ear Editor,

we read the publication on Antibodies to extractable nuclear antigens (ENAS) in systemic lupus erythematosus patients: correlations with clinical manifestations and disease activity with a great interest (1). Emad et al. noted that:

\section{Antibodies to ENAs are associated with clinical aspects of SLE and may play a role in the assessment of disease activity. Insight into these ENAs may lead to new approaches to diagnostic testing, accurate evaluation of disease activity and lead to target approach for SLE (1).}

In this work, Emad et al. clearly studied the association of the laboratory value and clinical findings but they did not focus and did not study the diagnostic property of the ENAs test. To select a test, a good diagnostic property is required. According to the report by Bentow et al. (2), the sensitivity of ENAs test is only $54.7 \%$, which is not considered a good test in laboratory medicine. The high false result occurrence means inaccuracy and this fact is discordant with the conclusion by Emad et al. (1).

\section{Conflict of interest: None}

\section{REFERENCES}

1. Emad Y, Gheita T, Darweesh H, et al. Antibodies to extractable nuclear antigens (ENAS) in systemic lupus erythematosus patients: correlations with clinical manifestations and disease activity. Reumatismo. 2018; 70: 85-91.

2. Bentow C, Swart A, Wu J, et al. Clinical performance evaluation of a novel rapid response chemiluminescent immunoassay for the detection of autoantibodies to extractable nuclear antigens. Clin Chim Acta. 2013; 424: 141-7. 